\title{
Ways to improve the anticorrosive properties of motor oils used in vehicles
}

\author{
Zebo Alimova ${ }^{1 *[10000-0002-6711-5318]}$, Ravshanjon Akhmatjanov ${ }^{1}$, Nargiza Kholikova $^{2}$, and \\ Kamola Karimova ${ }^{3}$ \\ ${ }^{1}$ Tashkent State Transport University, Tashkent, Uzbekistan \\ ${ }^{2}$ Tashkent Institute of Irrigation and Agricultural Mechanization Engineers, Tashkent, Uzbekistan \\ ${ }^{3}$ Jizzakh Polytechnic Institute, Jizzakh, Uzbekistan
}

\begin{abstract}
In recent years, increased requirements for protective properties have been imposed on petroleum oils for various purposes. One of the functions of the oil is to protect the surface of parts from corrosion. Corrosion becomes especially intense when the engine is operated in hot, humid climates. In this case, oil plays a double role: on the one hand, it protects the surfaces of parts from the aggressive influence of the external environment; on the other hand, the oil itself is corrosive due to the presence of corrosive substances in it.

Corrosion is especially intensified after the engine is stopped. When it cools, moisture condenses on the parts, the lubricating oil, flowing down from the lubricated surface, cannot protect the metal from corrosion. The reason for the corrosive properties of oils is that they contain organic and inorganic acid peroxides and other oxidation products and sulfur compounds, alkalis, and water.

The purpose of this work is to study and improve the anti-corrosion properties of lubricants. With an increase in temperature, the combined action of oxygen in the air and water present in the lubricating oil causes rusting of the crankshaft, liner walls, cylinders of the internal combustion engine.

We have studied anticorrosive additives as an additive to improve the anticorrosion properties of oils. Dialkylphenyl orthophosphoric acid additive was used as such additives. The anticorrosive activity of these substances is related to their ability to orient themselves on the oil-water surface so that hydrophilic groups are firmly bound to water while the hydrocarbon radical remains in the oil.
\end{abstract}

\section{Introduction}

In recent years, increased requirements for protective properties have been imposed on petroleum oils for various purposes. One of the functions of the oil is to protect the surface of parts from corrosion. The high protective effect is based on the ability of oils to quickly displace active compounds from the metal surface, keep it in the bulk of the lubricant, and

\footnotetext{
*Corresponding author: zeboalimova7841@mail.ru
} 
form strong adsorption and chemisorption films on it which prevent the development of electrochemical processes. Petroleum-based oils are not capable of long-term protection of metals from electrochemical corrosion. Corrosion can be related to external and internal factors. The main internal factor is the chemical composition of the oil. Active sulfur compounds directly cause corrosion of metals; therefore, they must be removed during the refining of oil products. The content of active sulfur compounds is determined by a sample on a copper plate $\left(3\right.$ hours at $\left.50^{\circ} \mathrm{C}\right)$.

Sulfur oxides SOx, nitrogen oxides NOx, and water resulting from the combustion of hydrogen, which form mineral acids $\mathrm{H}_{2} \mathrm{SO}_{3}, \mathrm{H}_{2} \mathrm{SO}_{4}, \mathrm{HNO}_{3}$, enter the crankcase from the combustion chamber of the engine together with the exhaust gases into the crankcase, which causes corrosion of the engine lubrication system parts. Corrosion of metals, especially non-ferrous ones, is also caused by organic acids formed due to the oxidation of hydrocarbons.

It seems most realistic to combat corrosion of engine parts and corrosion-mechanical wear by introducing corrosion inhibitors into engine oils and creating working conservation oils.

Corrosion inhibitors are designed to protect the surface of engine parts from corrosion caused by organic and mineral acids formed during the oxidation of oil and additives. The mechanism of their action is the formation of a protective film on the surface of parts and the neutralization of acids.

\section{Materials and Methods}

In addition to temperature, the nature of oil oxidation is influenced by the specific conditions of its operation in the engine: large areas of contact between oil and air (oil films, fog, oil foaming in the crankcase). Iron, copper, lead have a catalytic effect on the oxidation process. The most intense oxidation is observed in relatively thin layers of oil on highly heated metal surfaces. Particularly dangerous is the corrosion of non-ferrous metal bearing shells, which acidic oxidation products and sulfur compounds can cause. At high temperatures, sulfur compounds become especially aggressive towards silver and lead.

The corrosiveness of oils increases significantly when they contain water, entering the crankcase from the atmosphere or the engine cooling system.

Corrosion becomes especially intense when the engine is operated in hot, humid climates. In this case, oil plays a double role: on the one hand, it protects the surfaces of parts from the aggressive influence of the external environment; on the other hand, the oil itself is corrosive due to the presence of corrosive substances in it.

The combined action of oxygen in the air and water present in the lubricating oil causes rusting of the crankshaft, liner walls, cylinders of an internal combustion engine, etc. Corrosion increases, especially after stopping the engine. When it cools, moisture condenses on the parts, lubricating oil flowing down from the lubricated surface cannot protect the metal from corrosion.

The corrosive aggressiveness of oils about lead bronze from which the crankshaft bearing shells are made is assessed by the breakdown on the lead plate. In this case, the loss of its mass is determined under the conditions of its presence in oil for 50 hours at $140^{\circ} \mathrm{C}$.

The temperature factor especially affects the rate of general corrosion. An increase in temperature from 20 to $80^{\circ} \mathrm{C}$ at $5 \%$ by volume of water causes an increase in corrosion from 0.1 to $0.25 \mathrm{~mm} /$ year. Suppose we assume that the permissible corrosion rate is 0.2 $\mathrm{mm} /$ year. In that case, this value is achieved at a temperature of $80^{\circ} \mathrm{C}$ by $2 \%$, and a further increase in the water content in the oil leads to a significant increase in the corrosion rate (Table 1). 
Table 1. Dependence of the rate of general corrosion of metal (St-20) on the amount of water in oil $\mathrm{M}-10 \mathrm{~V}_{2}$ and on temperature

\begin{tabular}{|c|c|c|c|c|c|c|c|}
\hline $\begin{array}{c}\text { Temperatura, } \\
{ }^{\circ} \mathrm{C}\end{array}$ & \multicolumn{7}{|c|}{ General corrosion rate, $\mathrm{mm} /$ year at water content, \% vol. } \\
\cline { 2 - 8 } & $0 \%$ & $0.5 \%$ & $1.0 \%$ & $2.0 \%$ & $5.0 \%$ & $10.0 \%$ & $50 \%$ \\
\hline 20 & 0.050 & 0.060 & 0.065 & 0.078 & 0.104 & 0.204 & 0.496 \\
\hline 40 & 0.065 & 0.078 & 0.098 & 0.122 & 0.188 & 0.466 & 0.850 \\
\hline 60 & 0.065 & 0.104 & 0.098 & 0.124 & 0.204 & 0.504 & 1.244 \\
\hline 80 & 0.100 & 0.107 & 0.135 & 0.196 & 0.253 & 0.608 & 1.723 \\
\hline
\end{tabular}

To combat corrosion, special additives are added to the oils. Anti-corrosion additives are mainly polar substances that easily adsorb to metal surfaces.

The mechanism of their action is to create a protective monomolecular layer on the metal, which prevents acidic and other active agents from acting on the metal.

There is a relationship between the value of adsorption and surface tension at constant temperature and pressure:

$$
G=-\frac{a}{R T} \frac{d y}{d a}
$$

Where: $G$ is the surface concentration (the amount of substance accumulated per unit of interface); a is activity of the solute; dy is change in surface tension; $\mathrm{R}$ is universal gas constant; $\mathrm{T}$ is absolute temperature.

If an increase in the solute concentration leads to a decrease in surface tension, then the solute accumulates at the interface (positive adsorption). Conversely, if the surface tension increases with increasing the solute concentration, then the solute is removed from the interface (negative adsorption).

Polar groups capable of hydrating, dissolving and orienting in polar solvents are called hydrophilic; they may have sour or main character:

- $\mathrm{COOH},-\mathrm{OSO}_{3} \mathrm{H},-\mathrm{SO}_{3} \mathrm{H},-\mathrm{OH},-\mathrm{NH}_{2},-\mathrm{NHR},-\mathrm{N}(\mathrm{R})_{2}-\mathrm{N}+(\mathrm{R})_{3}, \mathrm{R}_{2} \mathrm{O}, \mathrm{R}-\mathrm{CONHR}$

Hydrophobic non-polar or weakly polar structural elements, soluble in non-polar organic solvents, are most often alkyl chains (straight or branched), aromatic monopolycyclic groups, or alkyl aromatic radicals.

In the oil-water system, the molecules of compounds having hydrophilic and hydrophobic groups are oriented as follows: 


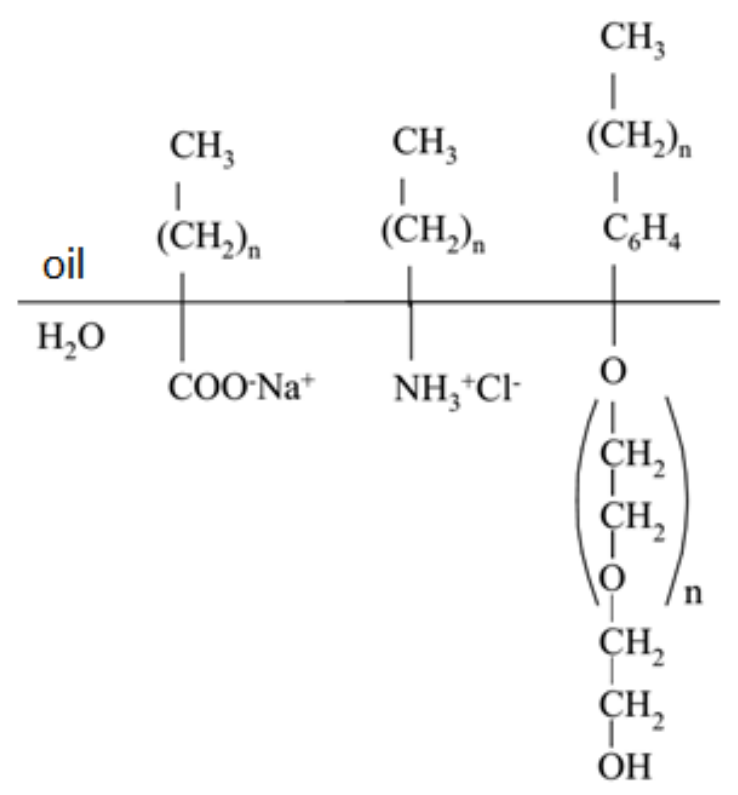

The physical characteristics of these systems are very important in terms of the effectiveness of surfactants used as anti-corrosive agents.

Such substances include high molecular weight fatty acids, salts of fatty and naphthenic acids, hydroxy acids, amines, etc. The introduction of surfactants into hydrocarbon media should, therefore, first of all, increase the wettability of metals in the oil-water system and create conditions for inhibitors to show the main functional property. The wetting ability of surfactants can manifest itself due to the formation of strong hydrogen bonds with water and displacement of water from the metal surface.

Before giving recommendations on the use of any additives, it is necessary to study their mechanism of action, without knowledge of which their effective use is impossible. The chemical composition of petroleum products and the additives they contain determine the composition and corrosiveness of the electrolyte formed during operation.

When the oil burns, high molecular weight organic acids are formed, which have a detrimental effect on metals in the presence of oxygen. Oxygen is part of peroxides; therefore, in the presence of oxygen and water, the metal undergoes electrochemical dissolution.

In this case, the corrosion process occurs in the form of a chemical reaction:

$$
\begin{gathered}
\mathrm{Me}+\mathrm{H}_{2} \mathrm{O}+0,5 \mathrm{O}_{2}=\mathrm{Me}(\mathrm{OH})_{2} \\
\mathrm{Me}(\mathrm{OH})_{2}+2 \mathrm{RCOOH}=\mathrm{Me}(\mathrm{RCOO})_{2}+2 \mathrm{H}_{2} \mathrm{O}
\end{gathered}
$$

where Me is metal.

The indicator of the corrosion resistance of the oil is the acid number, which should not exceed $0.4 \mathrm{mg}$ of caustic potassium $\mathrm{KOH}$ (potassium hydroxide) per $1 \mathrm{~g}$ of oil.

In corrosive terms, this concentration is practically not dangerous. Due to the high molecular weight, the acids in the fresh oil dissociate weakly, and the acids formed during the oxidation of the oil become the most dangerous since their low molecular weight has increased corrosiveness due to good solubility in water and better dissociation.

Anti-corrosion additives are mainly polar substances that easily adsorb to metal surfaces. Such substances include high molecular weight fatty acids, salts of fatty and naphthenic acids, hydroxy acids, amines, etc. The most active additives of this type are 
surface-active compounds such as sodium salts of petroleum sulfonic acids, esters of stearic and other fatty acids, as well as dibasic fatty acids, some nitrogen- and phosphoruscontaining compounds, for example, compounds of the $\mathrm{RSO}_{2} \mathrm{NHCOO} \mathrm{C}_{4} \mathrm{H}_{9}$ type, dicyclohexylamine nitrite. Additives obtained by oxidation of ceresin and petrolatum, containing esters and internal esters, are very effective.

Substances used as anticorrosive additives are salts of organic acids, metal phenates, various thiophosphoric compounds, and some other surface-active compounds. The introduction of surface-active compounds into hydrocarbon media should, therefore, first of all, increase the wettability of metals in the oil-water system and create conditions for the inhibitors to display their main functional properties. The following additives have practical application.

Calcium Alkyl Salicylate:<smiles>[R]Cc1ccc(O)c(C(=O)OC(=O)OOC(=O)c2cc(C=[R])ccc2O)c1</smiles>

where $\mathrm{R}=\mathrm{C}_{14}-\mathrm{C}_{18}$

Calcium alkylaryl sulfonate:<smiles></smiles>

The action of alkyl sulfates depends on the structure and length of the carbon chain and the position of the sulfo-ether group. Thus, they are greatly reduced with the branching of the carbon chain due to which alcohols and olefins with a straight chain of carbon atoms are used for the synthesis of alkyl sulfates. The ability is observed in alkyl sulfates with a terminal position of the sulfoester group and gradually decreases as this group is further from the end of the chain.

Nitrogen-containing compounds, aromatic amines $\mathrm{C}_{6} \mathrm{H}_{5} \mathrm{NH}_{2}$, which are derivatives of ammonia, deserve considerable attention as an anticorrosive additive.

Amines displace water from the metal surface by the following mechanism:



In this case, the primary reaction between the ROO- or $\mathrm{R}$ - radical and the amine molecule is the addition of this radical to the nitrogen atom, which has a pair of free electrons: 


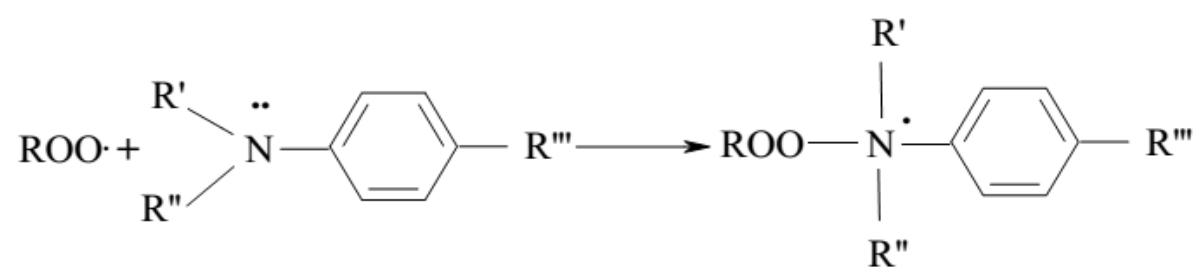

This complex radical reacts with another radical ROO· or R·, forming stable products, leading to the termination of the oxidative chain.

In this case, the activity of water molecules adsorbed on the metal surface will be significantly reduced. The displacement of water from the metal surface can occur as a result of its binding: due to solvation by metal cations, the inclusion of hydrophilic additives in the hydration shells, and solubilization or emulsification and stabilization in the form of water - oil product emulsions. The disadvantage of these additives is their poor solubility in oils.

\section{Results and Discussion}

As an anticorrosive additive, we studied a mixture of barium alkylphenolate and a zinc salt of dialkylphenyl dithiophosphoric acid-containing complex and internal esters. These products, unlike other additives, dissolve well in petroleum products, possessing several valuable properties necessary for lubricants.

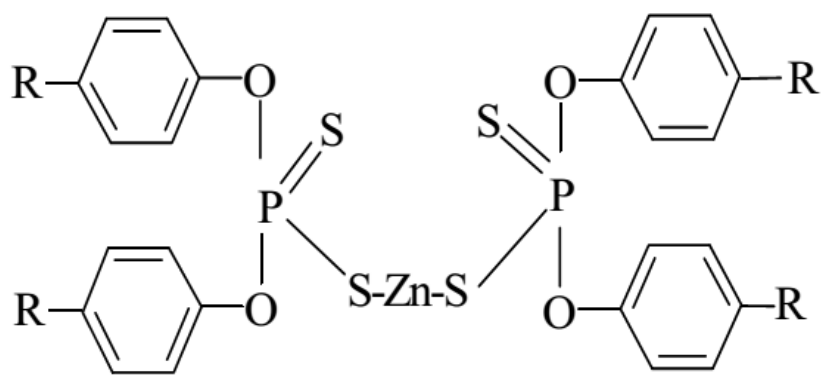

Research has shown that this compound has several advantages over other additives.

The anticorrosive activity of these additives is related to their ability to orient themselves on the oil-water surface so that hydrophilic groups are firmly bound to water while the hydrocarbon radical remains in the oil. The wetting ability of such additives can be manifested through the formation of strong hydrogen bonds with water and the displacement of water from the metal surface. The displacement of water from the metal surface can occur as a result of its binding: due to solvation by metal cations, the inclusion of hydrophilic additives in the hydrate shells, as well as due to solubilization or emulsification and stabilization in the form of water - oil product emulsions.

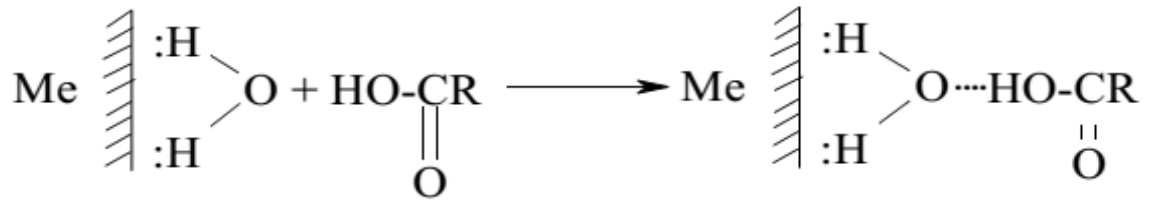


With these additives, it was possible to double the oil life. To achieve the desired effect, it is required to apply it in quantities of $1-2 \%$.

We have analyzed $\mathrm{M}-10 \mathrm{~B}_{2}$ motor oils and anti-corrosive additives of dialkylphenyl dithiophosphoric acid. After the introduction of this concentration of the additive into the oil, we observed its dissolution. Having determined the dissolution of the additives in the engine oil, we determined the physicochemical parameters of the engine oil for various concentrations of additives.

According to the results of laboratory studies, when the additive was introduced into the engine oil, they gave a positive result. The results showed a fairly high level of required properties for lubricants. In addition to the generally accepted properties, the speed of the water-displacing, protective and antiwear properties of the oil solutions of the obtained compounds were evaluated.

From the analysis results, we selected an additive content of $1.4 \%$, which shows the optimal value of the base number. The alkaline properties of the oil are characterized by the base number, determined by the amount of potassium hydroxide - $\mathrm{KOH}$ (caustic potassium), which is equivalent to the amount of hydrochloric acid $\mathrm{HCl}$ consumed to neutralize all the basic compounds contained in $1 \mathrm{~g}$ of oil. The alkaline number is expressed in $\mathrm{mg} \mathrm{KOH}$ per $1 \mathrm{~g}$ of oil, and, according to GOST, it should not exceed 2-6 mg.

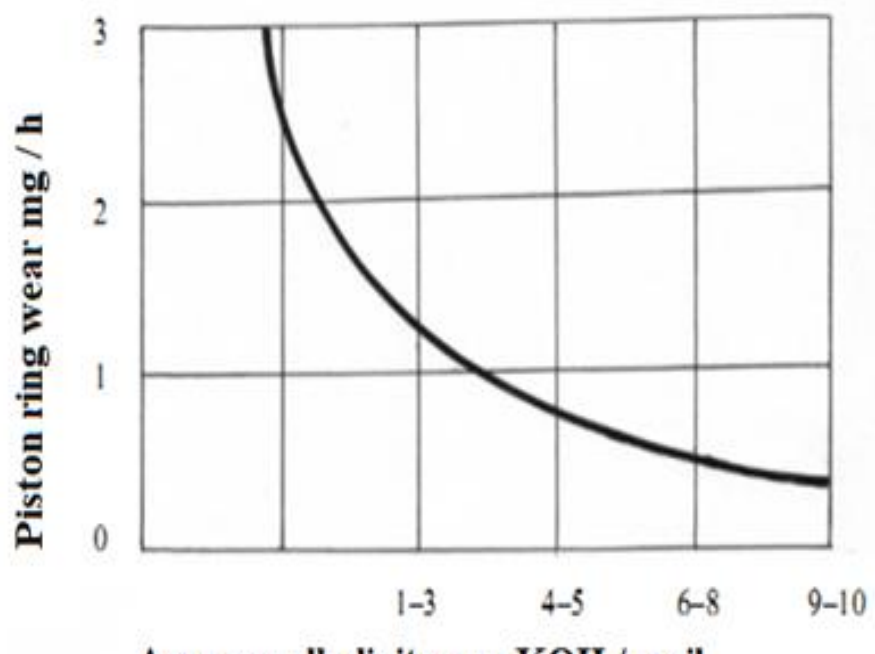

Average alkalinity, $\mathrm{mg} \mathrm{KOH} / \mathrm{g}$ oil

Fig. 1. Piston ring wear versus base number

Figure 1 shows that with an increase in the neutralizing (alkaline) ability of the oil, the wear of the piston rings sharply decreases. The base number decreases with decreasing additive concentration. At the same time, acidic products accumulate in the oil, which increases the corrosive wear of parts.

Based on the studies carried out, it can be assumed that the obtained corrosion inhibitors, displacing water from the metal surface, form strong adsorption-chemisorption films on it, which prevent the metal from contacting the electrolyte.

Thus, the mechanism of action of the proposed corrosion inhibitors based on dialkylphenyl dithiophosphoric acid is reduced to their ability to orient themselves on the oil-water surface so that hydrophilic groups are firmly bound to water, and the hydrocarbon radical remains in the oil. In this case, the activity of inhibitors is the greater, the more hydrocarbon atoms the radical contains. 
From the analysis results, we selected an additive content of $2.5 \%$, which shows the optimal value of the base number. At the same time, the base number increased to 5.3.

With a further increase in concentration, the viscosity increases strongly, leading to increased frictional losses.

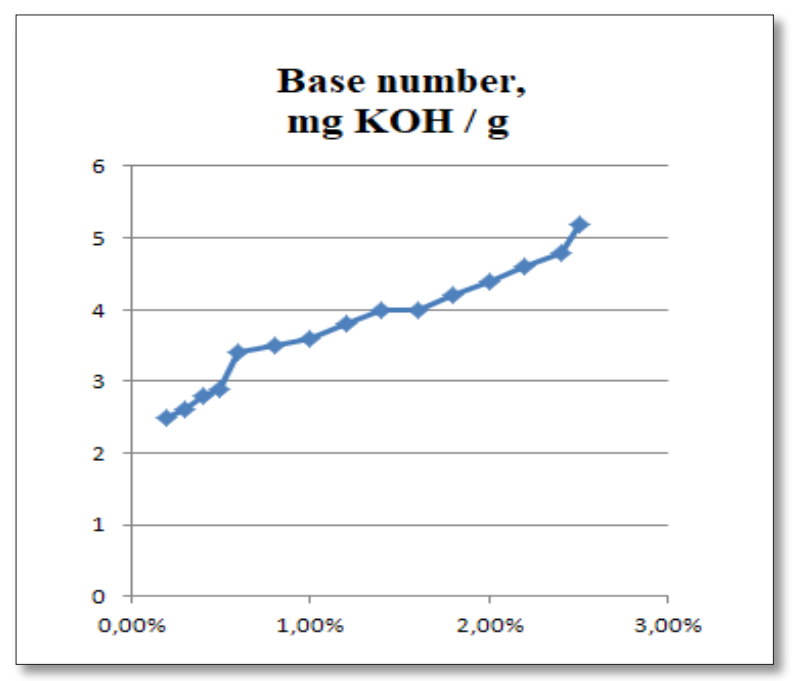

Fig. 2. Change in oil viscosity at $100^{\circ} \mathrm{C}$ depending on the concentration of additives.

Therefore, the main function of alkaline oil additives is to neutralize acids and protect the metal from corrosion. Therefore, one of the signs indicating the need to change the oil may decrease the base number.

With a further increase in concentration, the viscosity increases strongly, leading to increased frictional losses.

\section{Conclusions}

1. From the studies carried out, the following conclusion can be drawn: the corrosion inhibitors we have obtained displace water from the metal surface and, at the same time, form strong adsorption-chemisorption films that prevent the metal from contacting the electrolyte.

2. The proposed corrosion inhibitors based on dialkylphenyl dithiophosphoric acid can orient themselves on the oil-water surface so that hydrophilic groups are firmly bound to water, and the hydrocarbon radical remains in the oil. From the analysis results, we selected an additive content of $2.5 \%$, which shows the optimal value of the base number of 5.3. 


\section{References}

1. Dzherikhov V.B. Automotive operational materials: textbook. St. Petersburg: SPGASU, (2009)

2. Magerramov A.M., Akhmedova R.A., Akhmedova N.F. Petrochemistry and Oil Refining: A Textbook for Higher Educational Institutions, Baku: Baki Universiteti, (2009)

3. Ostrikov V.V., Kleimenov O.A., Bautin V.M. Lubricants and their quality control in the agro-industrial complex - M.: Rosinformatekh, p. 172, (2008)

4. Alimova Z. Research of change of quality of motor oils when operating the engine and improving their. Industrial Technology and Engineering. 3 (36), pp.11-17, (2020)

5. Danilov V.F. Oils, lubricants and special fluids. Study guide Elabuga: publishing house of the K (P) FU branch. (2013)

6. Alimova Z. Improvement of properties of oils used in hydraulic systems of roadconstruction equipment/ IOP Conference Series: Materials Science and Engineering 883, p. 012167, (2020)

7. Alimova Z. Ways to improve the properties of lubricants used in vehicles "VNESHINVESTROM", (2020)

8. Alimova Z. The Influence of the Process Off Oxidation of Engine Oils on Engine Performance and Improving Antioxidant Properties, Acta of Turin Polytechnic University in Tashkent. 8, №. 1, pp. 17, (2018)

9. Imomov S., Alimova, Z., Nuritov, I., and Temirkulova, N. Oil Purification Devices Used in Internal Combustion Engines. International Journal of Innovative Technology and Exploring Engineering, 9(1), pp. 3103-3107, (2019)

10. Alimova, Z., Kholikova N., and Xolova S. Ways to improve the performance of hydraulic oils for agricultural machinery Research Archive (30). (2020)

11. Imomov, S., Kholikova, N., Alimova, Z., Nuritov, I., and Temirkulova N. Oil Purification Devices Used in Internal Combustion Engines, Scientific Research Archive, 30, (2020).

12. Alimova, Z. The Influence of the Process Off Oxidation of Engine Oils on Engine Performance and Improving Antioxidant Properties. Acta of Turin Polytechnic University in Tashkent, 8(1), p. 17, (2018)

13. Alimova, Z. The Influence of The Process Off Oxidation of Engine Oils on Engine Performance and Improving Antioxidant Soust, Acta of Turin Polytechnic University in Tashkent, 8(2), pp. 50-53, (2018)

14. Kubaymurat, I., and Gulomovna, K.K. The Impact of Automobile Tires on the Environment from the Period of Raw Materials to the Disposal of Them, International Journal of Recent Technology and Engineering, 8(3), (2019).

15. Ismayilov, K., and Karimova, K. Application of used automobile tires granules for road construction in Uzbekistan. Journal of Critical Reviews, 7(12), pp. 946-948, (2020)

16. Grigoriev M.A. Engine oil quality and engine reliability, Publishing house of standards, p. 232, (2009)

17. Kirichenko N.B. Automotive Maintenance Materials Textbook for secondary vocational education, Moskva, Iz.Centre "Academy", (2012)

18. Rudnik L. R. Additives for lubricants, Properties and applications, In A. M. Danilova (ed.), Saint-Petersburg, COP Professiya, p. 928, (2013)

19. Grishin N.N., Sereda V.V. Encyclopedia of chemical, p. 960 Moskva, (2016)

20. Polkanov I.P. Methodical manual for improving methodological research, p. 86 Ul'yanovsk, USKHI, (1986) 